\title{
Decreased and aberrant nuclear lamin expression in gastrointestinal tract neoplasms
}

\author{
S F Moss, V Krivosheyev, A de Souza, K Chin, H P Gaetz, N Chaudhary, H J Worman, \\ P R Holt
}

\begin{abstract}
Background-Altered expression of lamins $A / C$ and $B 1$, constituent proteins of the nuclear lamina, may occur during differentiation and has also been reported in primary lung cancer.

Aims-To examine the expression of these proteins in gastrointestinal neoplasms.

Patients-Archival human paraffin wax blocks and frozen tissue from patients undergoing surgical resection or endoscopic biopsy.
\end{abstract}

Methods-Immunohistochemistry and western blotting using polyclonal antisera against $A$ type lamins and lamin $B 1$.

Results-The expression of lamin A/C was reduced and was frequently undetectable by immunohistochemistry in all primary colon carcinomas and adenomas, and in 7/8 primary gastric cancers. Lamin B1 expression was reduced in all colon cancers, 16/18 colonic adenomas, and 6/8 gastric cancers. Aberrant, cytoplasmic labelling with both antibodies occurred in some colonic cancers and around one third of colonic adenomas. Cytoplasmic lamin A/C expression was detected in $3 / 8$ gastric cancers. Lamin expression was reduced in gastric dysplasia, but not intestinal metaplasia, atrophy, or chronic gastritis. Lamin expression was low in carcinomas of oesophagus, prostate, breast, and uterus, but not pancreas.

Conclusions-Reduced expression of nuclear lamins, sometimes together with aberrant, cytoplasmic immunoreactivity is common in gastrointestinal neoplasms. Altered lamin expression may be a biomarker of malignancy in the gastrointestinal tract.

(Gut 1999;45:723-729)

Keywords: nuclear lamins; biomarkers; gastrointestinal neoplasms

The nuclear lamina is a meshwork of $10 \mathrm{~nm}$ diameter filaments located on the inner aspect of the inner nuclear membrane. ${ }^{1}$ The lamina is composed of proteins termed lamins that are members of the intermediate filament family. ${ }^{2-5}$ The lamina is disassembled and reassembled in a stepwise fashion during mitosis and lamins are degraded in cells undergoing apoptosis. ${ }^{67}$

Lamins have been classified as A type and B type based on their isoelectric points. ${ }^{89}$ In humans, one A type and two B type lamin genes have been identified. The gene that encodes the A type lamins A and C, isoforms that arise by alternative RNA splicing, is located on chromosome 1q21.2-21.3. ${ }^{10} 11 \mathrm{~A}$ third alternatively spliced lamin $\mathrm{C}$ variant that is expressed only in germ cells may also arise from this gene. ${ }^{12}$ Lamin B1 is encoded by a gene on chromosome 5q23.2-31.3. ${ }^{10} 13 \mathrm{~A}$ second $\mathrm{B}$ type lamin gene that encodes lamin B2 is located on chromosome $19 \mathrm{p} 13.3 .{ }^{14} \mathrm{~A}$ germ cell specific B type lamin may arise from lamin B2 by alternative RNA splicing. ${ }^{15}$ Examination of the lamin $\mathrm{A} / \mathrm{C}$ and lamin $\mathrm{B} 1$ gene promoters indicates that regulatory regions not yet characterised are responsible for the differential expression of these lamin genes in various cells and tissues. ${ }^{16}$

The results of numerous studies suggest that B type lamins are expressed to some extent in essentially all normal somatic cells while A type lamins are absent from early embryos and several non-terminally differentiated cells. ${ }^{17-26}$ Preliminary studies have indicated that lamin expression may be reduced in some cancers. ${ }^{27-29}$ For example, in a series of primary lung carcinomas, Broers et $a l^{29}$ found decreased expression of B type lamins in 11 of 23 non-small cell lung cancers, and reduced expression of A type lamins in 13 of 15 small cell lung cancers, raising the possibility that the determination of nuclear lamin expression in bronchial carcinoma may be of potential clinical benefit. ${ }^{30}$

Whether expression of nuclear lamins is altered in other carcinomas has not been investigated in detail. Because of the potential use of lamin expression as a tumour marker, we therefore examined lamin expression in gastrointestinal and some other common human epithelial malignancies and, in particular, colonic and gastric neoplasms, as the intermediate pathological steps in the multistage process of these cancers are readily identifiable. ${ }^{31}{ }^{32}$ Our aim was to determine the frequency of altered expression of nuclear lamins in gastrointestinal tract neoplasia, and to evaluate how early changes in nuclear lamin expression occur during the progression from normal mucosa to cancer.

\section{Methods}

TISSUE SAMPLES

A total of 108 human tissue blocks, identified by pathology records, were selected from the clinical pathology archives of St Luke'sRoosevelt Hospital Centre. Specimens of normal tissue were either endoscopic biopsy specimens taken from patients with normal findings or tissues resected surgically for non-inflammatory, non-neoplastic disease. 

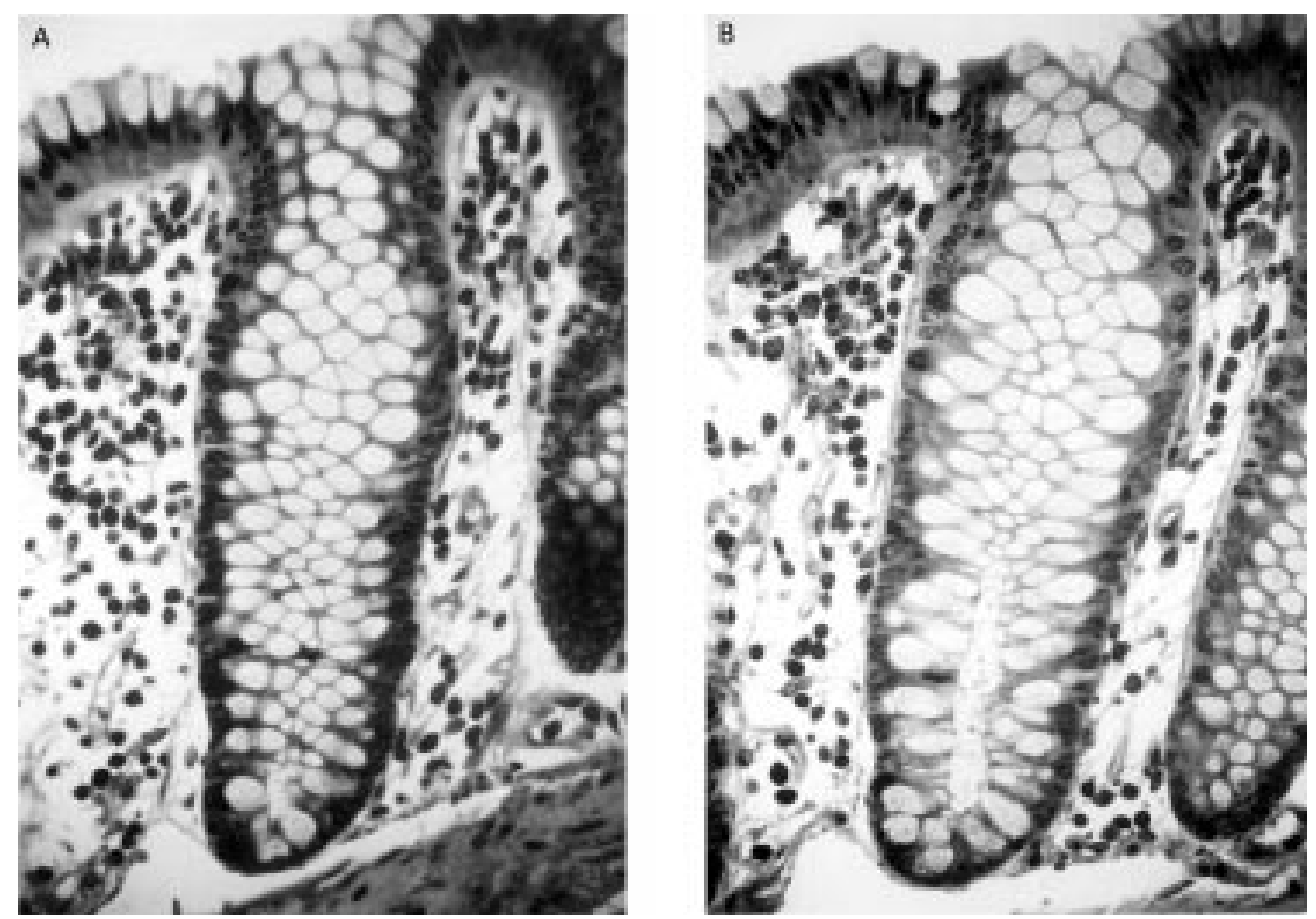

Figure 1 Normal colonic crypt immunostained for lamin $A / C(A)$ and lamin B1 (B) showing dark nuclear membrane staining in both epithelial cells and lamina propria cells. Lamin A/C is most highly expressed in cells in the upper crypt. Original magnification $\times 400$.

IMMUNOHISTOCHEMISTRY

Sections ( $4 \mu \mathrm{m}$ thick) of formalin fixed, paraffin wax blocks were cut onto "Superfrost-Plus" coated microscope slides (Fisher Scientific, Pittsburgh, Pennsylvania, USA). After deparaffinisation through xylenes, sections were washed and then exposed to microwave pretreatment (in $10 \mathrm{mM}$ citrate buffer, $\mathrm{pH} 6$ at 850 $\mathrm{W}$ for two periods of five minutes) to enhance antigenicity. Non-specific binding was blocked with 1/10 normal goat serum (Vector Laboratories, Burlingame, California, USA) in phosphate buffered saline; sections were incubated with polyclonal antibody to lamin $\mathrm{A} / \mathrm{C}$ or to lamin B1 overnight at a concentration of $1 / 300$ at $4^{\circ} \mathrm{C}$ for 18 hours. The antibodies used were raised in rabbits to sequence specific peptides conjugated to $\mathrm{KLH} .{ }^{28}{ }^{33}$ The peptide sequences used for immunisation were: GSVTKKRKLESTESC for lamin $\mathrm{A} / \mathrm{C}^{3}$ and TTRGKRKRVDVEESC for lamin B $1 .{ }^{34}{ }^{35}$ The cysteines at the carboxyl termini of the lamin peptides were not part of the sequences but added to each peptide for conjugation experiments not described in this study. Detection of binding of primary antibody was achieved using a biotinylated antirabbit IgG (Vector) and the streptavidin-peroxidase complex (ABC kit, Vector) with nickel diaminobenzene as chromogen. Finally, sections were lightly counterstained with $1 \%$ eosin and mounted. As a negative control, tissue sections were immunostained in the absence of the primary antibody, and as positive controls, a small section of normal colonic mucosa was stained at the edge of the microscope slides with each case.

QUANTITATION AND STATISTICAL ANALYSIS

The degree of immunointensity was quantified using a four point scale ( 0 , no staining; 1 , weak staining; 2, moderate staining; 3, very strong, intense staining). For each case, the entire stained tissue section was scanned and representative areas of epithelial cells examined at high power and ascribed a score, based on mean epithelial cell nuclear staining intensity. Comparison was made in all cases between the mean epithelial cell nuclear staining intensity of neoplastic cells compared with the mean epithelial cell nuclear staining intensity of normal tissues from patients without neoplasia. Statistical comparisons were made by the MannWhitney U test. Pairwise comparisons were also performed for epithelial cells in colon cancer with the histologically normal colonic crypt cells, either at the edge of the tumour in the same block or in the resection margin of the same operative specimen. Differences between carcinoma and normal cells in the same patient were assessed using Wilcoxon's signed ranks test.

\section{IMMUNOBLOTTING}

Fresh tissue obtained at surgery from seven patients with colon cancer was immediately snap frozen in liquid nitrogen and stored at $-80^{\circ} \mathrm{C}$. Samples were taken both from the carcinoma and the macroscopically normal appearing resection margin for each patient. The frozen tissue was then homogenised in liquid nitrogen and lysed in a buffer containing protease inhibitors as described previously, ${ }^{36}$ and the resulting insoluble material removed by centrifugation. Protein concentrations were measured by the Bradford method and $100 \mu \mathrm{g}$ protein samples were electrophoresed on $9 \%$ sodium dodecyl sulphate (SDS) polyacrylamide gels. ${ }^{37}$ Proteins were transferred to nitrocellulose membranes by electrotransfer and blocked for one hour at room temperature in Tris buffered saline, $\mathrm{pH} 7.6$, containing $1 \%$ 
A

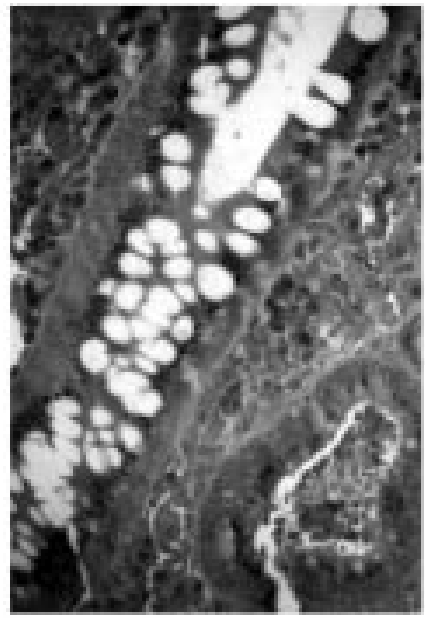

C

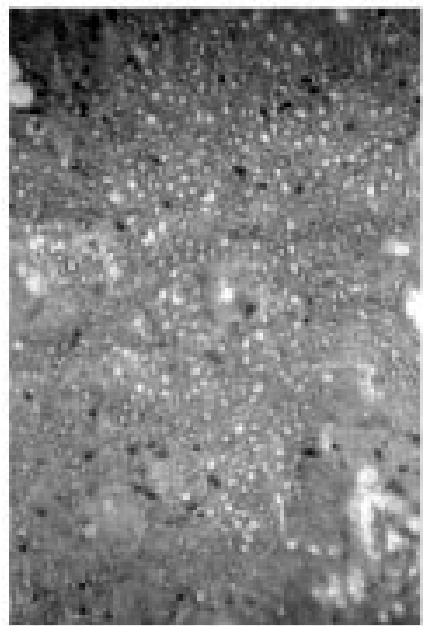

E

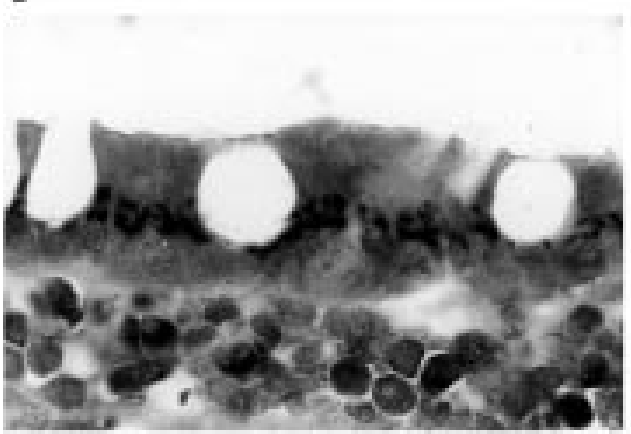

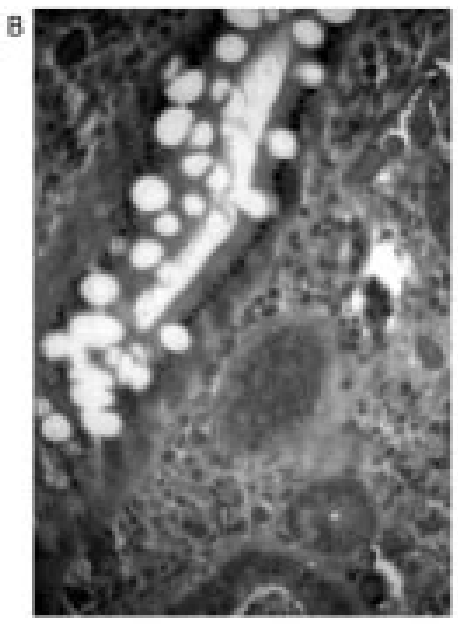

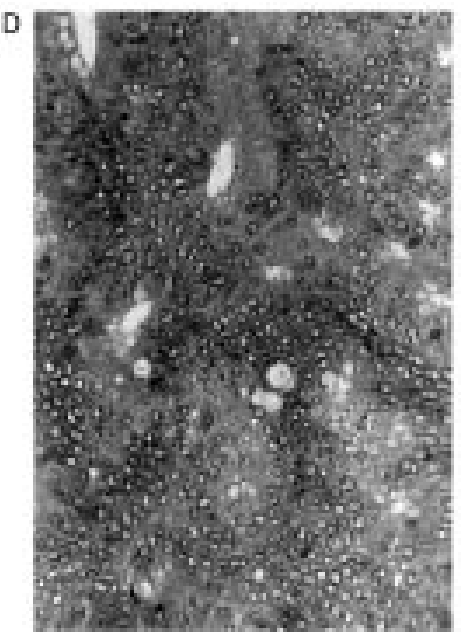

F

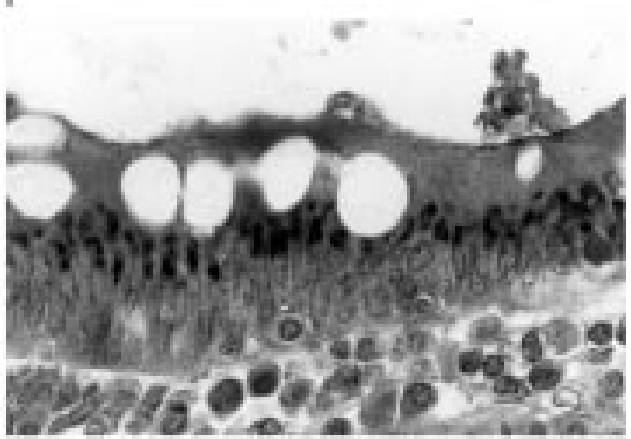

Figure 2 Expression of lamins in colon neoplasms. There is absent nuclear immunoreactivity with antibodies against lamin $A / C(A)$ and $B 1(B)$, and cytoplasmic labelling of lamin $A / C(A)$ and $B 1(B)$ in the gland of an adenomatous colonic polyp. In a colonic adenocarcinoma, lamin $A / C$ is absent $(C)$ and lamin $B 1$ notably reduced (D). Original magnification $\times 400$. The cytoplasmic immunolabelling of lamin $A / C(E)$ and lamin $B 1(F)$ between the nucleus and apical pole of adenomatous epithelial cells is better appreciated at higher magnification $(\times 1000)$.

Tween and 5\% skim milk, and incubated with antibody at a concentration of $1 / 300$ ( $\mathrm{vol} / \mathrm{vol}$ ); binding was detected with the ECL chemiluminescence system (Amersham, Arlington Heights, Illinois, USA).

\section{Results}

COLON

Fourteen cases of normal colonic mucosa (five from the ascending colon, five from the descending colon, and four from the rectum), 17 cases of primary colorectal carcinoma with adjacent transitional mucosa, and 18 cases of adenomatous polyps with adjacent transitional to normal mucosa were studied. Of the cases of colon carcinoma, three were Dukes's stage A, three Dukes's B, and the remainder Dukes's C; all were moderately differentiated, except two which were poorly differentiated. Lamin immunoreactivity in non-neoplastic mucosa was evident as a homogeneous band around the nucleus, in the location of the nuclear envelope. In some cells, particularly with high staining intensity, the entire nucleus labelled positively. Lamin A/C immunoreactivity was present in the nuclei of all cells of the colonic crypt. Staining was most intense (grade 3 ) in cells located in the surface $30-50 \%$ of the 
Table 1 Immunohistochemical nuclear labelling for lamins $A / C$ and lamin B1 in normal and neoplastic epithelial cells of gastric and colonic tissue sections

\begin{tabular}{llll}
\hline & $n$ & Lamin A/C & Lamin B1 \\
\hline Colon & & & \\
$\quad$ Normal & 14 & $2(1-3)$ & $3(1-3)$ \\
$\quad$ Adenoma & 18 & $0(0-1)^{\star \star}$ & $1(0-1)^{\star \star}$ \\
$\quad$ Adenocarcinoma & 17 & $0(0-1)^{\star \star}$ & $1(0-2)^{\star \star}$ \\
Stomach & & & \\
$\quad$ Normal & 6 & $2(1-3)$ & $2(2-3)$ \\
$\quad$ Intestinal metaplasia & 4 & $2(1-2)$ & $2(2-3)$ \\
$\quad$ Atrophy & 2 & $2(1-2)$ & $2(1-3)$ \\
$\quad$ Dysplasia & 4 & $1(1-2)$ & $2(1-2)$ \\
Adenocarcinoma & 8 & $0(0-1)^{\star}$ & $0(0-1)^{\star}$ \\
\end{tabular}

The degree of immunointensity was quantified using a four point scale. Data are shown as median (range); $\mathrm{n}=$ number of cases examined.

${ }^{\star} \mathrm{p}<0.05,{ }^{\star \star} \mathrm{p}<0.01$ compared with normal mucosa from the same organ.

colonic crypt (fig 1A). Immunoreactivity for lamin B1 was also evident in the nuclear membrane throughout the crypt. In contrast to lamin $\mathrm{A} / \mathrm{C}$ expression, there was no particular gradient from top to bottom of the crypt with lamin B1 (fig 1B).

In all colonic neoplasms (both adenoma and carcinomas), reduced or absent staining for lamin $\mathrm{A} / \mathrm{C}$ was observed (fig $2 \mathrm{~A}, \mathrm{C}, \mathrm{E}$; tables 1 and 2 ). In addition to notably reduced nuclear staining, lamin $\mathrm{A} / \mathrm{C}$ immunoreactivity was present in the epithelial cell cytoplasm in 39\% of the adenomatous polyps (fig $2 \mathrm{~A}, \mathrm{E}$ ), and in two of 17 carcinomas (table 2). Lamin B1 immunoreactivity was similarly reduced in colonic neoplasms. Sixteen of 18 adenomas and all 17 carcinomas had reduced nuclear lamin B1 labelling compared with control colonic mucosa. Lamin B1 immunoreactivity was undetectable in seven of 18 adenomas, and seven of 17 carcinomas (fig 2B,D,F). Again, cytoplasmic labelling with antilamin B1 antibodies was noted in some adenomas and carcinomas. In the transitional, histologically normal, mucosa immediately adjacent to the neoplasm, lamin immunoreactivity was similar to normal, but with occasional cytoplasmic labelling with antilamin $\mathrm{A} / \mathrm{C}$ and antilamin B1 antibodies. The expression of lamins in hyperplastic polyps was similar to normal colonic crypts.

Pairwise comparison between the carcinoma and histologically normal mucosa was possible in 15 of the 17 cases. For lamin $\mathrm{A} / \mathrm{C}$ the median immunointensity in the cancer was 0 (range $0-1)$ compared with $2(1-3)$ in the normal mucosa; immunointensity for lamin B1 was 1 $(0-1)$ and $2(2-3)$ respectively $(p<0.001$ in each case). The extent of reduction in nuclear lamin expression compared with normal was not related to the degree of differentiation or Dukes's stage of the primary carcinoma in this study, although comparison was limited because we examined very few cases which were not moderately differentiated or of Dukes's stage C.

Western blotting showed the expected size protein bands, with two proteins of around 65 and $74 \mathrm{kDa}$ detected with the lamin $\mathrm{A} / \mathrm{C}$ antibody and a single species of around $70 \mathrm{kDa}$ with lamin B1 (fig 3). No consistent differences in the detection of either lamin were observed by immunoblotting, when comparing normal mucosa with colon cancer.

\section{STOMACH}

We examined six cases of normal gastric tissue including specimens from the gastric antrum, corpus, and fundus. Gastric epithelial cells from all these regions stained strongly with both lamin A/C and lamin B1 antisera (fig $4 \mathrm{~A}, \mathrm{~B})$, regardless of site of origin. Eight cases of non-cardia gastric cancer were also studied. With regard to cancer of the colon, there was reduced expression of both lamin $\mathrm{A} / \mathrm{C}$ and lamin B1, although cytoplasmic staining was only noted for lamin $\mathrm{A} / \mathrm{C}$ and not for lamin B1 (fig 4C,D; tables 1 and 2). To establish where in the progression from normal through the progressively intermediate steps of gastric preneoplasia and neoplasia the reduction in lamin expression occurs, we also examined cases of gastric atrophy $(n=2)$, intestinal metaplasia $(n=4)$, and gastric dysplasia $(n=4)$. Both lamins were detected at normal levels in gastric atrophy and intestinal metaplasia, but in dysplasia all cases had reduced expression of lamins $\mathrm{A} / \mathrm{C}$ compared with normal mucosa, and two of four cases had reduced lamin B1. These results suggest that the reduction of lamin expression during gastric carcinogenesis occurs at the stage of gastric dysplasia.

Table 2 Immunohistochemical labelling for lamins A/C and B1 in tumour tissues, compared with normal epithelial cells of the same organ

\begin{tabular}{|c|c|c|c|c|c|c|}
\hline & \multicolumn{3}{|l|}{ Lamin $A / C$} & \multicolumn{3}{|l|}{ Lamin B1 } \\
\hline & \multicolumn{2}{|l|}{ Nuclear } & \multirow[b]{2}{*}{ Cytoplasmic } & \multicolumn{2}{|l|}{ Nuclear } & \multirow[b]{2}{*}{ Cytoplasmic } \\
\hline & Reduced & Absent & & Reduced & Absent & \\
\hline \multicolumn{7}{|l|}{ Colonic } \\
\hline Adenoma & $18 / 18(100 \%)$ & $15 / 18(83 \%)$ & $7 / 18(39 \%)$ & $16 / 18(89 \%)$ & $7 / 18(39 \%)$ & $5 / 18(28 \%)$ \\
\hline Adenocarcinoma & $17 / 17(100 \%)$ & $14 / 17(82 \%)$ & $2 / 17(12 \%)$ & $17 / 17(100 \%)$ & $7 / 17(41 \%)$ & $3 / 17(18 \%)$ \\
\hline Gastric adenocarcinoma & $7 / 8(88 \%)$ & $4 / 8(50 \%)$ & $3 / 8(38 \%)$ & $6 / 8(75 \%)$ & $4 / 8(50 \%)$ & $0 / 8(0 \%)$ \\
\hline \multicolumn{7}{|l|}{ Oesophageal cancer } \\
\hline Squamous & $3 / 6(50 \%)$ & $3 / 6(50 \%)$ & $0 / 6(0 \%)$ & $3 / 5(60 \%)$ & $0 / 6(0 \%)$ & $0 / 6(0 \%)$ \\
\hline Adenocarcinoma & $2 / 2(100 \%)$ & $1 / 2(50 \%)$ & $0 / 2(0 \%)$ & $1 / 2(50 \%)$ & $1 / 2(50 \%)$ & $0 / 2(0 \%)$ \\
\hline Pancreatic cancer & $0 / 3(0 \%)$ & $0 / 3(0 \%)$ & $1 / 3(33 \%)$ & $0 / 3(0 \%)$ & $0 / 3(0 \%)$ & $0 / 3(0 \%)$ \\
\hline Cervical squamous carcinoma & $3 / 3(100 \%)$ & $3 / 3(100 \%)$ & $0 / 3(0 \%)$ & $2 / 3(67 \%)$ & $0 / 3(0 \%)$ & $0 / 3(0 \%)$ \\
\hline Uterine adenocarcinoma & $3 / 3(100 \%)$ & $3 / 3(100 \%)$ & $0 / 3(0 \%)$ & $2 / 3(67 \%)$ & $1 / 3(33 \%)$ & $0 / 3(0 \%)$ \\
\hline Prostate adenocarcinoma & $3 / 4(75 \%)$ & $0 / 4(0 \%)$ & $0 / 4(0 \%)$ & $3 / 4(75 \%)$ & $0 / 4(0 \%)$ & $0 / 4(0 \%)$ \\
\hline Breast adenocarcinoma & $3 / 3(100 \%)$ & $0 / 3(0 \%)$ & $0 / 3(0 \%)$ & $3 / 3(100 \%)$ & $0 / 3(0 \%)$ & $0 / 3(0 \%)$ \\
\hline Lung non-small cell carcinoma & $3 / 3(100 \%)$ & $2 / 3(67 \%)$ & $0 / 3(0 \%)$ & $2 / 3(67 \%)$ & $2 / 3(67 \%)$ & $3 / 3(100 \%)$ \\
\hline
\end{tabular}

Nuclear lamin expression in neoplastic cells was compared with that found in the nuclei of normal epithelial cells from the same tissue and the data presented as the percentage of cases with reduced and/or absent nuclear lamin expression. Aberrant cytoplasmic expression is also noted as a percentage of neoplastic cases examined. 


$$
\frac{1}{N \quad C} \frac{2}{N \quad C} \frac{3}{N \quad C}
$$

$\operatorname{Lamin} A / C$
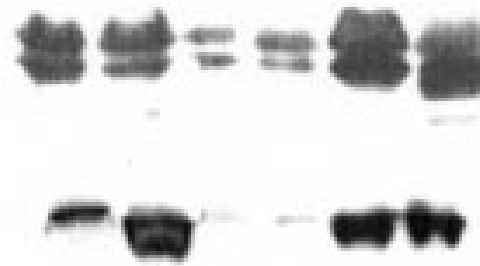

$$
\text { ( }
$$

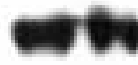

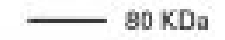

Figure 3 Representative immunoblot of normal $(N)$ and cancer $(C)$ tissue pairs from three patients with primary colorectal carcinoma. No consistent differences in the expression of lamin A/C or B1 were found in these tissue lysates. Migration of molecular mass standards in kilodaltons is shown on the right.

OTHER NEOPLASMS

A small number of other neoplasms were examined. Table 2 summarises the findings. In the normal oesophagus, lamin $\mathrm{A} / \mathrm{C}$ and $\mathrm{B} 1$ were expressed in all epithelial cells; lamin B1 expression was particularly strongly expressed in cells of the basal layer. In squamous oesophageal cancer, lamin B1 expression was maintained, but lamin $\mathrm{A} / \mathrm{C}$ expression lost in four of six cases. In adenocarcinoma lamin $\mathrm{A} / \mathrm{C}$ immunoreactivity was reduced in both cases and lamin B1 in one of the two cases. No cytoplasmic lamin labelling was observed in oesophageal cancer.
In the normal human pancreas, very weak expression of both types of lamin was noted in acinar cells and in the ductular epithelium. The islets of Langerhans stained weakly for lamin $\mathrm{B} 1$ expression, and no lamin $\mathrm{A} / \mathrm{C}$ was detectable. In contrast to findings in the oesophagus, stomach, and colon, carcinoma of the pancreas had retained expression of lamin $\mathrm{A} / \mathrm{C}$ and $\mathrm{B} 1$ and, indeed, lamin B1 expression was greater than the normal intensity of acinar and ductular cells in two of three cases examined.

In both cervical and uterine body cancer, lamin $\mathrm{A} / \mathrm{C}$ expression was reduced compared with the normal uterine epithelium. Lamin B1 expression was similar to normal in cervical cancer but reduced or absent in cancer of the uterine body. The expression of both types of lamins was reduced compared with normal in three cases of breast cancer and in three of four cases of prostatic cancer studied. In non-small cell lung cancer $(n=3)$ and in one case of small cell lung cancer, reduced expression of both lamins was observed, compared with the normal lung.

\section{Discussion}

This study clearly shows that lamin $\mathrm{A} / \mathrm{C}$ and lamin B1 immunoreactivity is reduced in colonic and gastric adenocarcinomas. A reduction in lamin expression by immunohistochemistry was found to occur at an intermediate stage of neoplastic transformation in both these organs and, concomitant with reduced lamin
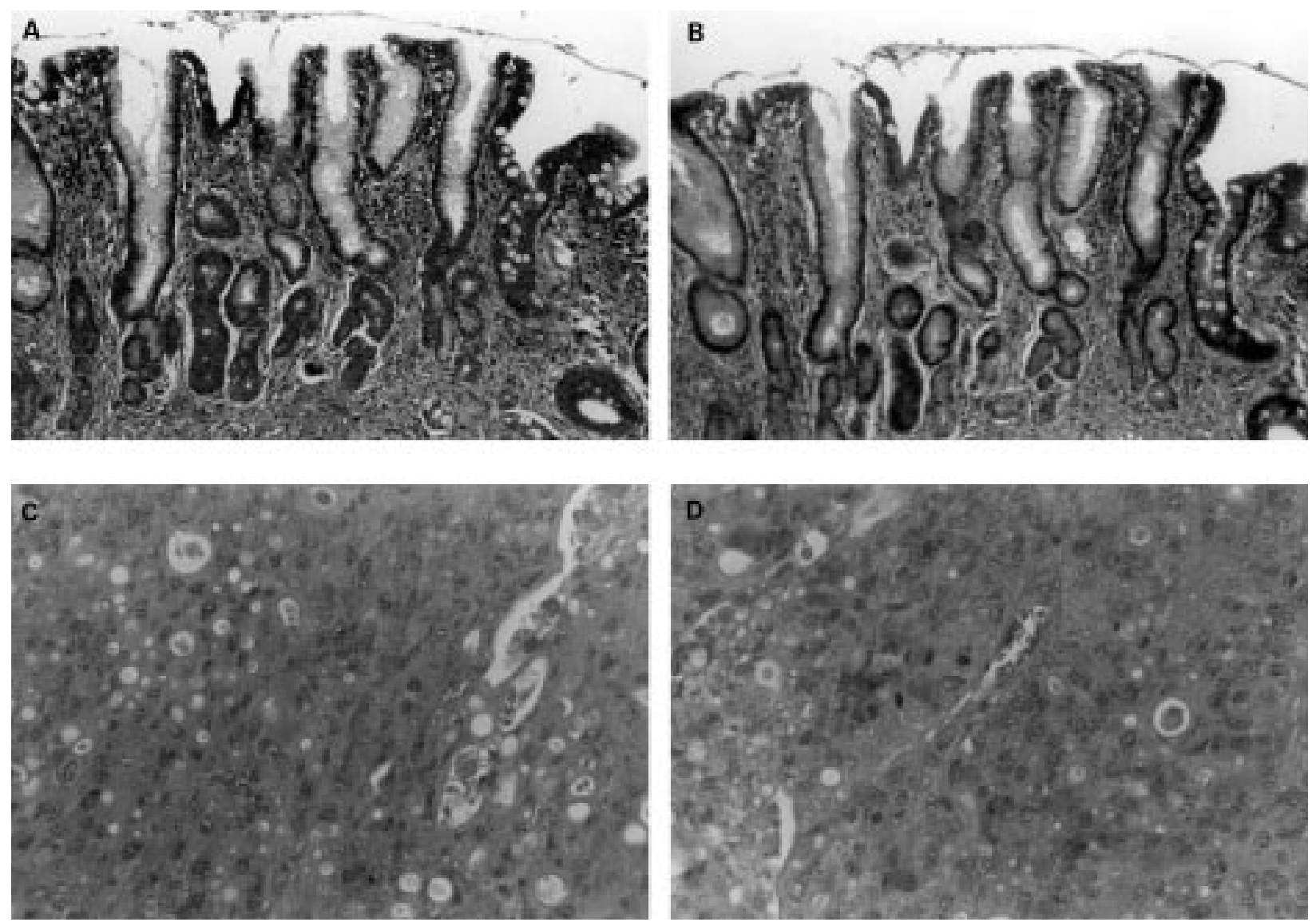

Figure 4 Expression of nuclear lamins in gastric tissue. In the non-neoplastic mucosa from a gastrectomy specimen removed for cancer, strong expression of nuclear lamin $A / C(A)$ and $B 1(B)$ is evident throughout, including both the relatively normal mucosa on the left and in the area of intestinal metaplasia, on the right. There is notably reduced expression of lamin $A / C(C)$ and $B 1(D)$ in an intestinal type gastric cancer. Original magnification $\times 400$. 
expression, cytoplasmic immunolabelling for both types of lamin was often observed. The latter finding has only previously been reported for A type lamins in small cell lung cancers, ${ }^{29}$ and the functional significance of this finding is not known.

Although we found notably reduced immunohistochemical lamin expression in neoplastic gastric and colonic epithelial cells in comparison with the normal epithelial cells of these organs, this was not confirmed by western blotting tissue lysates of colonic neoplasms and the histologically uninvolved surgical resection margin. This suggests that immunoblotting is a relatively insensitive way to detect altered epithelial cell expression of lamins, probably due to the presence of contaminating non-epithelial cells in the tissue lysates, as noted previously. ${ }^{28}$ However, the possibility remains that despite reduced nuclear lamin expression in cancers, total cell lamin immunoreactivity may be unchanged due to aberrant aggregation of lamins in the cytoplasm of transformed cells. Furthermore, in spite of the fact that we frequently failed to detect nuclear lamin expression in cancer by immunohistochemistry, it is likely that small amounts of lamins may continue to be expressed in neoplastic cells, albeit below the limit of detection of our immunohistochemical assay.

From examining a small series of other common solid human cancers, we have found that a reduction in expression of both lamin $\mathrm{A} / \mathrm{C}$ and $\mathrm{B} 1$ appears to be a frequent feature of carcinomas. We found reduced lamin expression in squamous and adenocarcinoma of the oesophagus, in cervical and uterine body cancers, in breast cancer, and also in bronchial carcinoma, the latter confirming a previous report. ${ }^{29}$ However, reduced lamin expression may not be a universal finding in all epithelial neoplasms, as we also found that the expression of A type lamins and lamin B1 was normal in pancreatic cancer, and others have similarly observed lamin expression to be maintained in five cases of hepatocellular carcinoma. ${ }^{38}$

The mechanism underlying reduced nuclear lamin expression is not evident from this study, but possible explanations for reduced nuclear lamin immunoreactivity include decreased nuclear lamin protein synthesis, alteration of normal nuclear lamin protein structure to a less immunoreactive form, or lamin protein degradation, as occurs during apoptosis. ${ }^{6}$

Similarly, the cause of the cytoplasmic labelling with antilamin antibodies that we observed is not known. It could signify mislocalisation of nuclear lamins in the cytoplasm or cytoplasmic aggregation of newly synthesised lamin proteins that cannot reach the nucleus.

The clinical significance of reduced nuclear lamin expression remains to be determined. We have not observed any change in nuclear lamin expression in inflammatory, non-neoplastic conditions such as Helicobacter pylori associated chronic gastritis, peptic oesophagitis, or diverticulitis. As our study suggests that reduced nuclear lamin expression may be an early event in gastrointestinal neoplasia, reduced nuclear lamin immunoreactivity and/or cytoplasmic lamin labelling could conceivably serve as a marker of the malignant phenotype in situations where conventional histological assessment is difficult. This would include the diagnosis of high grade dysplasia in Barrett's oesophagus and in the colon of patients with long standing ulcerative colitis. More detailed studies of nuclear lamin expression in these conditions are indicated in order to test such hypotheses.

In summary, we have found reduced nuclear lamin expression to be an early and frequent finding in gastrointestinal cancer, often accompanied by aberrant cytoplasmic immunolabelling. Although the cause of this phenomenon is currently not known, we speculate that reduced nuclear lamin expression may be useful as a marker of malignancy.

We are grateful to Larisa Ravitskaya and Anne Washington for technical assistance, and to Mary Felder for assistance with manuscript preparation. HJW is an Irma T Hirsch Scholar and was also supported by a grant (R01-CA66974) from the National Institutes of Health.

1 Aebi U, Cohn J, Buhle L, Gerace L. The nuclear lamina is a meshwork of intermediate-type filaments. Nature 1986;323:560-4.

2 McKeon FD, Kirschner MW, Caput D. Homologies in both primary and secondary structure between nuclear envelope and intermediate filament proteins. Nature 1986;319:463-8.

3 Fisher DZ, Chaudhary N, Blobel G. cDNA sequencing of nuclear lamins $\mathrm{A}$ and $\mathrm{C}$ reveals primary and secondary structural homology to intermediate filament proteins. Proc Natl Acad Sci USA 1986;83:6450-4.

4 Georgatos SD, Stournaras C, Blobel G. Heterotypic and homotypic associations between the nuclear lamins: ite-specificity and control by phosphorylation. Proc Natl Acad Sci USA 1988;85:4325-9.

5 Ye Q, Worman HJ. Protein-protein interactions between human nuclear lamins expressed in yeast. Exp Cell Res 1995;219:292-8

6 Kaufmann SH. Induction of endonucleolytic DNA cleavage in human acute myelogenous leukemia cells by etoposide, camptothecin and other cytotoxic anticancer drugs: a cautionary note. Cancer Res 1989;49:5870-8.

7 Chaudhary N, Courvalin J-C. Step-wise reassembly of the nuclear envelope at the end of mitosis. F Cell Biol 1993;122: 295-306.

8 Gerace L, Blobel G. The nuclear envelope lamina is reversibly depolymerized during mitosis. Cell 1980;19:277-87.

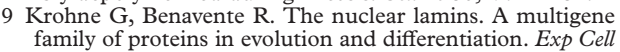
Res 1986;162:1-10.

10 Wydner KL, McNeil JA, Lin F, et al. Chromosomal assignment of human nuclear envelope protein genes LMNA, $\angle M N B 1$, and LBR by fluorescence in situ hybridization. Genomics 1996;32:474-8.

11 Lin F, Worman HJ. Structural organization of the human gene encoding nuclear lamin A and nuclear lamin C. $\mathcal{F}$ Biol Chem 1993;268:16321-6.

12 Furukawa K, Inagaki H, Hotta Y. Identification and cloning of an mRNA coding for a germ cell-specific A-type lamin in mice. Exp Cell Res 1994;212:426-30.

13 Lin F, Worman HJ. Structural organization of the human gene LMNB1 encoding nuclear lamin B1. Genomics 1995; 27:230-6.

14 Biamonti G, Giacca M, Perini G, et al. The gene for a novel human lamin maps at a highly transcribed locus of chromosome 19 which replicates at the onset of S-phase. Mol Cell Biol 1992;12:3499-506.

15 Furukawa K, Hotta Y. cDNA cloning of a germ cell specific lamin B3 from mouse spermatocytes and analysis of its function by ectopic expression in somatic cells. EMBO $\mathcal{F}$ 1993;12:97-106.

16 Lin F, Worman HJ. Expression of nuclear lamins in human tissue and cancer cell lines and transcription from the promotors of the lamin A/C and B1 genes. Exp Cell Res 1997; 236:378-84

17 Guilly M-N, Kolb JP, Gosti F, et al. Lamins A and C are not expressed at early stages of human lymphocyte differentiation. Exp Cell Res 1990;189:145-8.

18 Guilly M-N, Bensussan A, Bourge JF, et al. A human T lymphoblastic cell line lacks lamins A and C. EMBO $\mathcal{f}$ 1987;6:3795-9.

19 Lebel S, Lampron C, Royal A, et al. Lamins A and C appear during retinoic acid-induced differentiation of mouse embryonal carcinoma cells. f Cell Biol 1987;105:1099-104. 
20 Stewart C, Burke B. Teratocarcinoma stem cells and early mouse embryos contain only a single major lamin polypep-

21 Paulin-Levasseur M, Scherbarth A, Traub U, Traub P. Lack of lamins $\mathrm{A}$ and $\mathrm{C}$ in mammalian hemopoietic cell lines devoid of intermediate filament proteins. Eur f Cell Biol 1988;47:121-31.

22 Paulin-Levasseur M, Giese G, Scherbarth A, et al. Expression of vimentin and nuclear lamins during the in vitro differentiation of human promyelocyte leukemia cells HL-60. Eur 7 Cell Biol 1989;50:453-61.

23 Paulin-Levasseur M, Scherbarth A, Giese G, et al. Expression of nuclear lamins in mammalian somatic cells lacking cytoplasmic intermediate filament proteins. $\mathcal{F} \mathrm{Cell}$ Sci 1989;92:361-70.

24 Worman HJ, Lazaridis I, Georgatos SD. Nuclear lamina heterogeneity in mammalian cells, differential expression of the major lamins and variation in lamin B phosphorylation. f Biol Chem 1988;263:12135-41.

25 Röber R-A, Stauter H, Weber K, et al. Cells of the cellular immune and hematopoietic system of the mouse lack lamins A/C: distinction versus other somatic cells. $7 \mathrm{Cell} \mathrm{Sci}$ ins A/C: distinction.

26 Röber R-A, Weber K, Osborn M. Differential timing of nuclear lamin $\mathrm{A} / \mathrm{C}$ expression in the various organs of the mouse embryo and the young animal: a developmenta study. Development 1989;105:365-78.

27 Kaufmann SH, Mabry M, Jasti R, et al. Differential expression of nuclear envelope lamins $\mathrm{A}$ and $\mathrm{C}$ in human lung cancer cell lines. Cancer Res 1991;51:581-6.

28 Cance WG, Chaudhary N, Worman HJ, et al. Expression of the nuclear lamins in normal and neoplastic human tissues. f Exp Clin Cancer Res 1992;11:233-46.
29 Broers JLV, Raymond Y, Rot MK, et al. Nuclear A-type lamins are differentially expressed in human lung cancer subtypes. Am f Pathol 1993;143:211-20.

30 Hirano T, Franzen B, Uryu K, et al. Detection of polypeptides associated with the histopathological differentiation of primary lung carcinoma. Br f Cancer 1995;72: $840-8$.

31 Fearon ER, Vogelstein B. A genetic model for colorectal tumorigenesis. Cell 1990;61:759-67.

32 Correa P. Human gastric carcinogenesis: a multistep and multifactorial process. First American Cancer Society Award lecture on cancer epidemiology and prevention. Cancer Res 1992;52:6735-40.

33 Chaudhary N, McMahon C, Blobel G. Primary structure of a human arginine-rich nuclear protein that colocalizes with spliceosome components. Proc Natl Acad Sci USA 1991;88: 8189-93.

34 Höger TH, Krohne G, Franke WW. Amino acid sequence and molecular characterization of murine lamin B as deduced from cDNA clones. Eur F Cell Biol 1988;47:283-90.

35 Pollard KM, Chan EKL, Grant BJ, et al. In vitro post-translational modification of lamin $\mathrm{B}$ cloned from a human T-cell line. Mol Cell Biol 1990;10:2164-75.

36 Guan RJ, Moss SF, Arber N, et al. 30kda phosphorylated form of Bcl-2 protein in human colon. Oncogene 1996;12: 2605-9.

37 Laemmli UK. Cleavage of structural proteins during the assembly of the head of bacteriophage T4. Nature 1970;270:680-5.

38 Hytiroglou P, Choi SW, Theise ND, et al. The expression of nuclear lamins in human livers: an immunohistochemical study. Hum Pathol 1993;24:169-72. 